\title{
Kajian Performa Passive Residual Heat Removal System (PRHRS) pada System-Integrated Advanced Modular Reactor (SMART)
}

\author{
Putu Brahmanda Sudarsana ${ }^{1}$, Wayan Nata Septiadi ${ }^{* 1}$, Mulya Juarsa*2 \\ ${ }^{1}$ Program Studi Teknik Mesin, Universitas Udayana, Kampus Bukit Jimbaran, Bali, Indonesia 80361 \\ ${ }^{2}$ Pusat Teknologi dan Keselamatan Reaktor Nuklir, Badan Tenaga Nuklir Nasional (BATAN), Gedung 80 Kawasan Puspitek, \\ Serpong, Tangerang Selatan, Banten, Indonesia 15310
}

\begin{tabular}{l}
\hline INFORMASI ARTIKEL \\
\hline Riwayat Artikel: \\
Diterima: \\
20 Mei 2021 \\
Diterima dalam bentuk revisi: \\
28 Juli 2021 \\
Disetujui: \\
30 Desember 2021
\end{tabular}

Kata kunci:

SMART

PRHRS

Sirkulasi Alami

Termohidrolika

LOCA

\begin{abstract}
ABSTRAK
KAJIAN PERFORMA PASSIVE RESIDUAL HEAT REMOVAL SYSTEM (PRHRS) PADA SYSTEM-INTEGRATED ADVANCED MODULAR REACTOR (SMART). SMART (SystemIntegrated Advanced Modular Reactor) merupakan desain reaktor multifungsi Generasi III+ tipe SMR (Small Modular Reactor) yang dikembangkan oleh KAERI (Korean Atomic Energy Research Institute) dengan kapabilitas produksi listrik $107 \mathrm{MWe}$ dan energi termal $365 \mathrm{MWt}$. Sistem SMART meliputi berbagai fitur keselamatan untuk mengatasi LOCA (Loss of Coolant Accident) dan skenario kecelakaan lainnya. Salah satu dari fitur tersebut adalah Passive Residual Heat Removal System (PRHRS) atau sistem pembuang sisa panas pasif yang bekerja tanpa membutuhkan sumber daya elektrik. Sistem ini bekerja sesuai dengan prinsip sirkulasi alam sehingga bergantung pada aspek termal, tekanan, dan pengaruhnya terhadap aliran massa. Ketiga aspek tersebut dapat mempengaruhi kapabilitas pembuangan panas pada sistem. Data performa PRHRS reaktor SMART pada beberapa kondisi kecelakaan yang diperoleh melalui studi eksperimental maupun simulasi termohidrolika dianalisis pada kajian ini. Hasil analisis menunjukkan unjuk kerja pembuangan sisa panas yang baik oleh PRHRS SMART dengan waktu aktuasi yang tepat dan pendinginan yang stabil. Dengan kapabilitas multifungsi dan kemampuan pendinginan yang baik pada berbagai skenario kecelakaan, SMART memiliki potensi tinggi untuk kelak diterapkan di Indonesia.
\end{abstract}

\begin{abstract}
STUDY ON PASSIVE RESIDUAL HEAT REMOVAL SYSTEM (PRHRS) PERFORMANCE OF SYSTEM-INTEGRATED ADVANCED MODULAR REACTOR (SMART). SMART (SystemIntegrated Advanced Modular Reactor) is a Generation III+ multifunctional SMR (Small Modular Reactor) design developed by KAERI (Korean Atomic Energy Research Institute) with the capability of $107 \mathrm{MWe}$ electric generation and $365 \mathrm{MWt}$ thermal energy. The SMART system comprises various safety features to prevent LOCA (Loss of Coolant Accident) and other accident scenarios. One of the features is Passive Residual Heat Removal System (PRHRS), which works without any electric source. This system works according to the natural circulation principle and thus depends on the thermal aspect, pressure aspect, and its influence on mass flow rate. These three aspects can affect the heat removal capability of the system. PRHRS performance data of SMART in several accident conditions, which are acquired through thermal-hydraulic experimental and simulation studies, are analyzed and studied in this paper. Results of the analysis show a well-desired heat removal performance of SMART PRHRS with punctual actuation and stable decrease of coolant temperature and pressure. With multi-function capability and decent cooling performance, SMART has a high potential to be implemented in Indonesia in the near future.

Keywords: SMART, PRHRS, Natural Circulation, Thermal-hydraulic, LOCA
\end{abstract}

\section{PENDAHULUAN}

Perkembangan teknologi dalam usaha menghasilkan energi bersih masih menjadi tantangan yang cukup berat. Hal ini diakibatkan oleh beberapa faktor di antaranya, faktor ekonomis, kapabilitas teknologi, dan sumber daya yang belum memadai. Dalam kategori

\footnotetext{
*Penulis korespondensi.
}

E-mail: juars@yahoo.com energi bersih, energi solar, angin, dan hidro merupakan pilihan utama dan paling dikenal masyarakat, dengan tingkat emisi gas rumah kaca di bawah $27 \mathrm{~g} \mathrm{CO}_{2}-\mathrm{eq} / \mathrm{kWh}$ [1]. Ditinjau dari emisi gas rumah kaca, energi nuklir juga masuk dalam kategori energi bersih dengan emisi gas $\mathrm{CO}_{2}$ pada kisaran $15 \mathrm{~g} \mathrm{CO}_{2}-\mathrm{eq} / \mathrm{kWh}$, namun belum cukup dikenal masyarakat. 
Selama periode 1970-2013, sebesar 163 Gt $\mathrm{CO}_{2}$ berhasil dikurangi melalui penggunaan sumber energi rendah karbon. Energi nuklir berkontribusi $41 \%$ dari pengurangan $163 \mathrm{Gt}$ $\mathrm{CO}_{2}$ tersebut [1]. Hal tersebut menunjukkan efektivitas energi nuklir sebagai energi bersih yang layak menjadi titik fokus perkembangan teknologi. Dari sudut pandang teknologi, Pembangkit Listrik Tenaga Nuklir (PLTN) dibagi menjadi 4 generasi: Generasi I (19501970) dengan fokus utama pengembangan design prototype; Generasi II (1970-1995) merupakan implementasi dari pembangkit komersial Light Water Reactor (LWR) dengan aplikasi desain paling banyak berupa Boiling Water Reactor (BWR) dan Pressurized Water Reactor (PWR); Generasi III/III+ (1995-2030) dengan peningkatan keamanan dan keselamatan reaktor berdasarkan pengalaman pengoperasian dari reaktor generasi II; dan Generasi IV (2030+) berupa konsep desain baru yang jauh berbeda dengan generasi sebelumnya [2], [3]. Keempat generasi desain reaktor tersebut menunjukkan pesatnya perkembangan teknologi energi nuklir dengan fokus pengembangan pada keselamatan, keamanan, efektivitas biaya, dan kemudahan komersialisasi.

Dalam kategori SMR Generasi III+, salah satu desain reaktor SMR yang telah memiliki lisensi (design approval) adalah SMART (System-Integrated Advanced Modular Reactor) yang dikembangkan oleh KAERI (Korean Atomic Energy Research Institute) sejak tahun 1996 dengan tujuan meningkatkan sistem keamanan dan nilai ekonomis [5], [6]. Pengembangan reaktor SMART tidak lepas dari pembelajaran terhadap kecelakaan reaktor Fukushima Daiichi. Penerapan sistem pembuang sisa panas pasif merupakan salah satu fitur yang dikembangkan pada reaktor SMART [5], [7], dengan bertitik tolak pada kegagalan sistem pendingin aktif yang memicu fuel meltdown pada kecelakaan PLTN Fukushima Daiichi. Fuel meltdown akibat kegagalan pendingin aktif tersebut memicu terjadinya reaksi antara uap air dengan material cladding (paduan zirkonium) sehingga menghasilkan gas hidrogen. Tingginya temperatur corium menyebabkan ledakan gas hidrogen sehingga zat-zat radioaktif menyebar luas melalui udara dan atmosfer [4]. Walaupun sistem pembuang sisa panas secara pasif telah dikembangkan jauh sebelum terjadinya kecelakaan reaktor Fukushima Daiichi, namun peristiwa kecelakaan reaktor tersebut menjadi dasar penguat implementasi sistem pendingin pasif serta penelitian terkait yang lebih intensif. Studi terhadap kestabilan aliran massa pada sistem pendingin pasif, khususnya sistem pembuang sisa panas pasif reaktor SMART, menjadi titik fokus karena kestabilan aliran berpengaruh terhadap kemampuan pembuangan panas saat kondisi kecelakaan. Prinsip kerja sistem pendingin pasif pada reaktor SMART menerapkan prinsip sirkulasi alam (natural circulation) yang terjadi akibat adanya driving force karena perbedaan ketinggian sumber panas dan pendingin pada sistem [8]-[11]. Melalui sirkulasi alam tersebut, panas sisa pada inti reaktor saat kondisi shutdown dapat didistribusikan keluar untuk mencegah overpressure atau bahkan fuel meltdown tanpa menggunakan mesin yang membutuhkan daya eksternal. Analisis stabilitas aliran dan performa sistem pembuang sisa panas pasif telah banyak dilakukan melalui simulasi dengan kode RELAP5/MOD3.2, MARS/SMR (restrukturisasi dari RELAP5/MOD3.2.1.2 dan COBRA-TF), MARSKS, TASS/SMR, MATRA, dan TASS/SMR-S [5], [7]-[9], [12]-[15]. Kerja sistem pembuang sisa panas pasif yang menerapkan prinsip sirkulasi alami tidak lepas dari pengujian dan validasi berdasarkan karakteristik termohidrolika. Dalam konteks ini, karakteristik termohidrolika sirkulasi alami dua fase pada sistem menjadi dasar validasi keamanan reaktor SMART [8]. Selama pengembangan reaktor SMART, KAERI melakukan pengujian termohidrolika menggunakan fasilitas eksperimental VISTAITL, fasilitas SCOP untuk pengujian aliran dalam reaktor SMART, fasilitas SWAT untuk evaluasi sistem keamanan injeksi, dan FTHEL untuk pengembangan kode desain teras SMART [10], [16]. Kode simulasi dan fasilitas eksperimental tersebut telah berkontribusi dalam perolehan lisensi/approval dari reaktor SMART.

Kajian naratif ini membahas sistem keamanan Reaktor SMART, khususnya pada sistem pembuang sisa panas pasif (PRHRS). Pembahasan sistem tersebut dilakukan dengan mengkaji artikel ilmiah terkait riset yang telah dilakukan terhadap sistem reaktor SMART baik 
melalui simulasi dengan kode tertentu maupun melalui fasilitas eksperimental oleh KAERI. Hasil kajian data performa PRHRS diinterpretasikan dari segi unsur keselamatan yang tertera pada dokumen teknis.

\section{SYSTEM-INTEGRATED ADVANCED MODULAR REACTOR (SMART)}

SMART merupakan desain reaktor Generasi III+ tipe SMR (Small Modular Reactor) yang dikembangkan oleh KAERI (Korean Atomic Energy Research Institute) dengan tujuan peningkatan daya saing ekonomi, modularisasi, simplifikasi desain, dan peningkatan sistem keamanan reaktor. Reaktor SMART didesain untuk keperluan multi-fungsi berupa produksi listrik, desalinasi air laut, serta sumber panas pada industri atau distrik tertentu. Kapabilitas produksi listrik reaktor SMART mencapai 107 MWe dengan penghasilan energi termal sebesar $365 \mathrm{MWt}$, sehingga cukup untuk memenuhi kebutuhan listrik dan air bersih untuk kota dengan populasi hingga 100000 penduduk [6]. Tabel 1 menunjukkan spesifikasi dari reaktor SMART. Sistem utama desain reaktor SMART sebagaimana ditunjukkan pada Gambar 1 meliputi inti reaktor dan bahan bakar, 8 generator uap, satu pressurizer, 4 pompa pendingin reaktor, dan 25 mekanisme kontrol batang kendali pada satu bejana tekan reaktor [6],[16]. Desain reaktor SMART yang lebih compact ini lebih aman karena berhasil mengeliminasi penggunaan sistem koneksi perpipaan pada sistem pendingin reaktor utama sehingga mencegah reaktor untuk mengalami LBLOCA (large break loss of coolant accident).

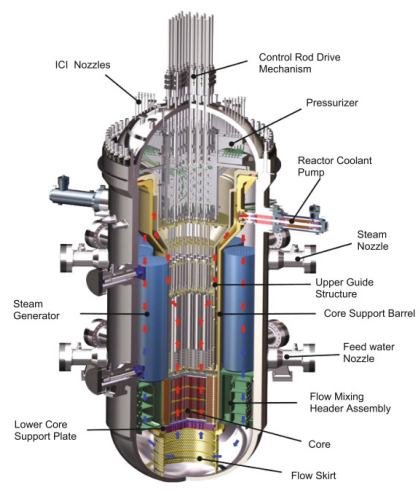

Gambar 1. Desain Tampak Potong Bejana Tekan Reaktor SMART [19].
Tabel 1 Spesifikasi Detail Reaktor SMART [5], [6], [18]

\begin{tabular}{|c|c|}
\hline Parameter & Nilai \\
\hline \multicolumn{2}{|c|}{ Parameter Utama } \\
\hline Pendingin/moderator & $\mathrm{H}_{2} \mathrm{O} / \mathrm{H}_{2} \mathrm{O}$ \\
\hline $\begin{array}{ll}\text { Kapasitas } & \text { termal/elektrik } \\
(\mathrm{MW}(\mathrm{t}) / \mathrm{MW}(\mathrm{e})) & \end{array}$ & $365 / 107$ \\
\hline Sirkulasi Primer & Sirkulasi Paksa \\
\hline Tekanan NSSS (Nuclear Steam & $15 / 5,8$ \\
\hline $\begin{array}{l}\text { Supply } \\
\text { (primer/sekunder) }(\mathrm{MPa})\end{array}$ & \\
\hline Tipe/susunan bahan bakar & $\begin{array}{c}\text { Pellet } \mathrm{UO}_{2} / \text { kotak } \\
17 \times 17\end{array}$ \\
\hline $\begin{array}{l}\text { Jumlah susunan bahan bakar } \\
\text { pada inti }\end{array}$ & 57 \\
\hline Pengayaan bahan bakar (\%) & $<5$ \\
\hline $\begin{array}{l}\text { Pembakaran pelepasan inti } \\
\text { (GWd/ton) }\end{array}$ & $<54$ \\
\hline Siklus pengisian ulang bahan & 30 \\
\hline
\end{tabular}

bakar (bulan)

Mekanisme kontrol reaktivitas

Pendekatan sistem keamanan

Umur pakai desain reaktor (tahun)

Luas sistem pembangkit $\left(\mathrm{m}^{2}\right)$

Tinggi/diameter bejana tekan reaktor $(\mathrm{m})$

Ketebalan rata-rata bejana tekan (mm)

Berat bejana tekan reaktor (ton)

Desain seismic (SSE)

Tipe pressurizer

Keperluan siklus bahan bakar

Status desain

Mekanisme penggerakan batang kendali dan larutan boron Pasif 60

90000

$18,5 / 6,5$

19,8

1070 (termasuk pendingin)

$>0,3 \mathrm{~g}$ dengan aktivasi shutdown pada $0,18 \mathrm{~g}$

Self-controlled

Kapasitas

penampungan bahan bakar sisa hingga 30 tahun

Terlisensi

(approved)

\begin{tabular}{|c|c|}
\hline \multicolumn{2}{|c|}{ Sistem Pendingin Reaktor } \\
\hline Tekanan desain/kerja (MPa) & $17 / 15$ \\
\hline Temperatur inti inlet/outlet $\left({ }^{\circ} \mathrm{C}\right)$ & $295,7 / 323$ \\
\hline $\begin{array}{l}\text { Aliran massa minimum pada inti } \\
(\mathrm{kg} / \mathrm{s})\end{array}$ & 2090 \\
\hline $\begin{array}{l}\text { Mekanisme penggerak batang } \\
\text { kendali }\end{array}$ & 25, linear step motor \\
\hline Kaset generator uap & 8, saluran helical \\
\hline Pompa pendingin reaktor & 4, canned-motor \\
\hline \multicolumn{2}{|c|}{ Sistem Sekunder } \\
\hline Tekanan desain/kerja (MPa) & $17 / 5,2$ \\
\hline $\begin{array}{l}\text { Sistem pembuang sisa panas } \\
\text { pasif (PRHRS) }\end{array}$ & 4 rangkaian \\
\hline Safety injection system (SIS) & 4 rangkaian \\
\hline Shutdown cooling system & 2 rangkaian \\
\hline $\begin{array}{l}\text { Chemical and volume control } \\
\text { system }\end{array}$ & 1 rangkaian \\
\hline
\end{tabular}




\section{METODOLOGI}

Metode kajian dilakukan secara deskriptif terhadap data pada beberapa sumber literatur. Dalam pencarian artikel pada jurnal dan dokumen teknis, keyword yang digunakan adalah "SMART", "SMART passive residual heat removal system", dan "SMART thermalhydraulic". Tahapan pengumpulan data dan penulisan kajian ditunjukkan pada Gambar 2. Data yang diperoleh pada sumber literatur meliputi skematik detail fasilitas eksperimental yang digunakan, skematik sistem pendingin pasif reaktor SMART, serta grafik-grafik yang mengandung data performa PRHRS SMART. Untuk meningkatkan tingkat akurasi analisis dan perolehan data pada titik tertentu, grafik akan dianalisa menggunakan WebPlotDigitizer. Penentuan efektivitas dan keamanan PRHRS reaktor SMART dilakukan berdasarkan interpretasi terhadap data pada jurnal dan dokumen teknis tersebut.

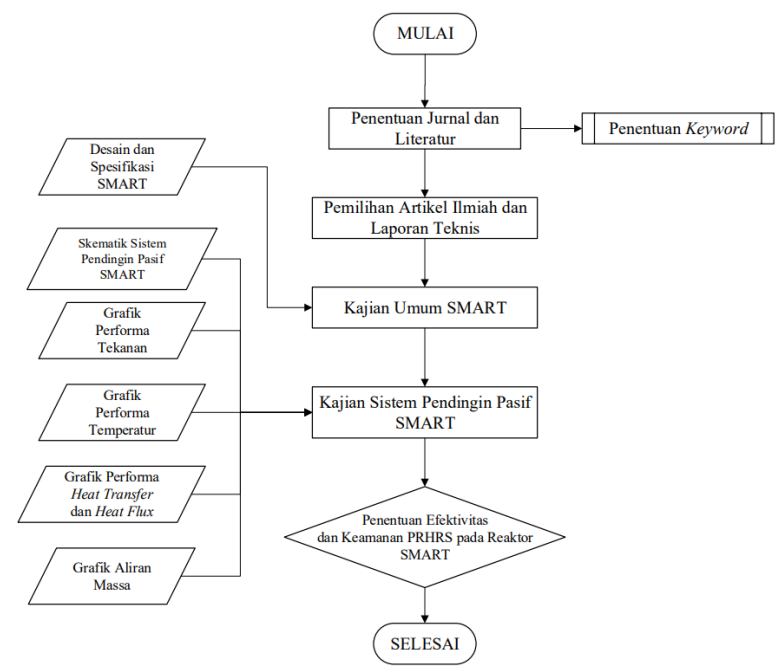

Gambar 2. Diagram Alir Tahapan Pengumpulan Data dan Penulisan Kajian.

\section{HASIL DAN PEMBAHASAN}

\subsection{Sistem Pembuang Sisa Panas Pasif (PRHRS) pada SMART}

Sistem pembuang sisa panas pasif atau passive residual heat removal system (PRHRS) merupakan salah satu integrasi sistem keamanan pada reaktor nuklir yang difungsikan untuk mendinginkan sumber panas (inti reaktor) melalui transfer energi pada fluida kerja yang mengalir tanpa adanya daya eksternal (non- electric). PRHRS difungsikan untuk secara terus menerus mampu mendinginkan reaktor selama kondisi operasi, darurat, hingga shutdown. Tujuan spesifik PRHRS adalah untuk membuang sisa panas pada inti reaktor dalam keadaan shutdown sehingga kondisi temperatur berada dibawah titik leleh material cladding [4]. Kegagalan dalam pendinginan kondisi temperatur inti reaktor akan menyebabkan pelepasan material radioaktif, atau dikenal dengan istilah fuel meltdown. Sistem pembuang sisa panas pasif meliputi inti reaktor, generator uap, compensating tank, emergency cooldown tank (ECT), sistem penukar panas (heat exchanger, IHX) sistem perpipaan yang meliputi check dan isolation valve (MFIV/MSIV) dan pipa [8], [20]. Pada PRHRS, generator uap akan menjadi sumber panas yang diletakkan di bagian bawah dan ECT sebagai pendingin akan diletakkan di atas sehingga terjadi sirkulasi alam. Sirkulasi alam atau natural circulation merupakan mekanisme perpindahan panas yang terjadi akibat gradien densitas dari fluida yang diperoleh melalui ketidakseimbangan temperatur [21]. Pada reaktor SMART, sistem PRHRS akan aktif saat supply feedwater atau ekstraksi uap air mengalami kegagalan serta saat reaktor dalam kondisi perbaikan dan refueling [8]. Aliran sirkulasi alam pendinginan generator uap pada PRHRS SMART ditunjukkan pada Gambar 3.

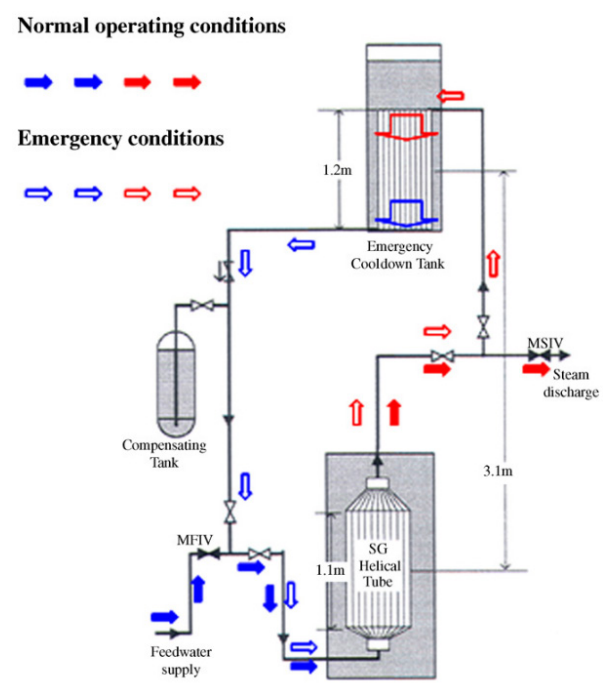

Gambar 3. Skematik PRHRS Reaktor SMART [20]

Desain sistem PRHRS reaktor SMART meliputi empat rangkaian dan mampu membuang panas hanya dengan dua rangkaian aktif selama 72 jam tanpa intervensi dari operator [5], [7]. Pada reaktor SMART, sistem 


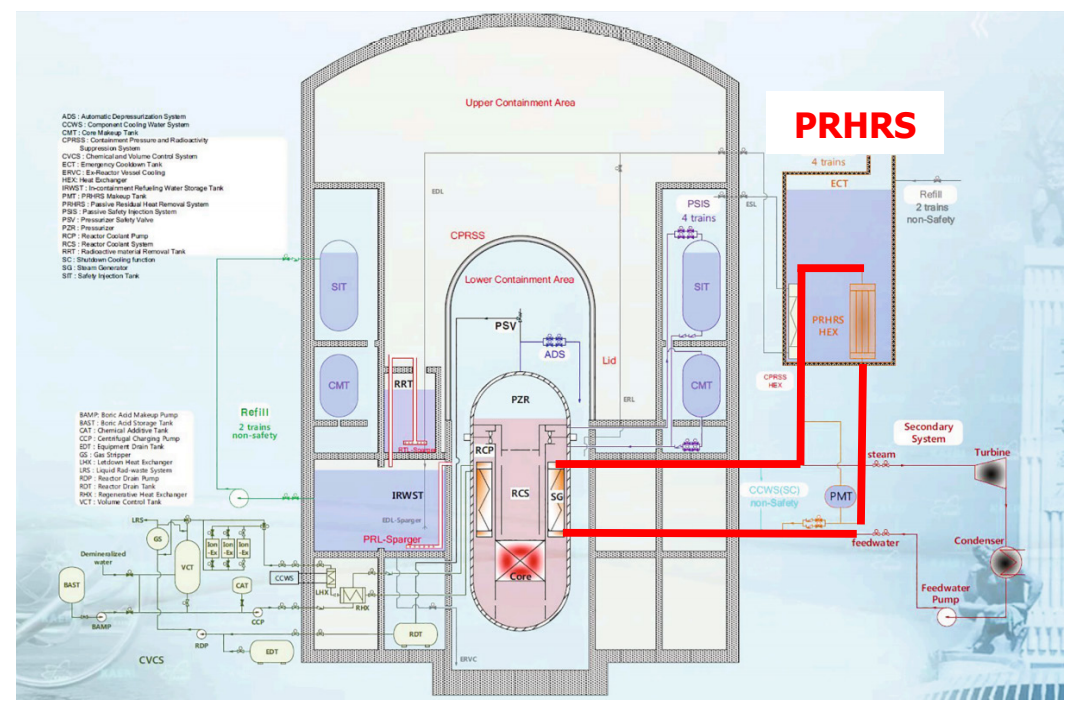

Gambar 4. Sistem PRHRS pada Reaktor SMART [19].

PRHRS merupakan sistem sekunder yang terdiri atas 4 rangkaian dengan kapasitas pembuangan panas sebesar 4.6 MW untuk setiap rangkaiannya (Gambar 4 dan Tabel 2). Pada kondisi awal sebelum trip reaktor, katup periksa yang tersambung pada tangki compensating dan sistem penukar panas, digunakan untuk mencegah terjadinya sirkulasi alam melalui pencegahan aliran balik menuju sistem penukar panas [7]. Saat terdeteksi keadaan darurat (ketidaktersediaan feedwater atau terperangkapnya uap), MSIV/MFIV akan tertutup dan sistem PRHRS akan tersambung pada generator uap melalui pembukaan katup pemutus. Air pada temperatur rendah akan masuk melalui bagian bawah generator uap, kemudian melalui saluran berbentuk helical dan menangkap panas yang terdapat pada generator uap. Air tersebut akan mengalami perubahan fase menjadi uap panas lanjut. Uap ini akan bergerak menuju ECT melalui saluran pipa uap akibat efek buoyancy. Fluida kerja air pada fase uap panas lanjut akan terkondensasi pada ECT. Fase uap panas lanjut kemudian berubah menjadi fase cairan jenuh sehingga dengan gaya gravitasi, air pada fase cairan akan kembali masuk ke saluran helical pada generator uap.

Tabel 2. Parameter Sistem PRHRS Reaktor SMART [7]

\begin{tabular}{lc}
\hline \multicolumn{1}{c}{ Parameter } & Nilai \\
\hline Jumlah rangkaian & 4 \\
Kapasitas pembuangan panas/rangkaian $(\mathrm{MW})$ & 4,6 \\
Total volume tangki compensating $\left(\mathrm{m}^{3}\right)$ & 2 \\
Volume gas $\mathrm{N}_{2}$ tangki compensating $\left(\mathrm{m}^{3}\right)$ & 0,3 \\
Tekanan tangki compensating $(\mathrm{MPa})$ & 5 \\
Volume air pada ECT $\left(\mathrm{m}^{3}\right)$ & 50 \\
\hline
\end{tabular}

Dalam analisis terhadap sistem PRHRS, aspek fenomena termohidrolika merupakan salah satu kunci untuk menguji unjuk kerja dari sistem tersebut. Pada sistem keamanan reaktor SMART, terdapat tiga fenomena yang teridentifikasi berkaitan dengan termohidrolika, antara lain perilaku fluida pada kolam besar, sirkulasi alam, serta perilaku dari sistem penukar panas darurat dan isolasi kondensor [22]. Karakteristik aspek termohidrolika yang berkaitan erat dengan kerja sistem PRHRS ditunjukkan pada Tabel 3. Aspek termohidrolika yang akan dibahas pada kajian ini meliputi aspek termal, tekanan, dan stabilitas aliran massa pada sistem PRHRS reaktor SMART.

Tabel 3. Karakteristik Termohidrolika pada Sistem PRHRS Reaktor SMART [22]

\begin{tabular}{|c|c|}
\hline Fenomena & $\begin{array}{c}\text { Karakteristik Aspek } \\
\text { Termohidrolika }\end{array}$ \\
\hline $\begin{array}{l}\text { Perilaku fluida (cairan) } \\
\text { pada ECT }\end{array}$ & $\begin{array}{l}\text { Stratifikasi termal } \\
\text { Konveksi/sirkulasi alami dan } \\
\text { paksa } \\
\text { Kondensasi uap } \\
\text { Transfer panas dan uap pada } \\
\text { bagian atas (vaporisasi) } \\
\begin{array}{ll}\text { Pengurasan cairan akibat } \\
\text { kebocoran ringan } \\
\text { (transportasi gas dan uap) }\end{array}\end{array}$ \\
\hline $\begin{array}{l}\text { Sirkulasi alam } \\
\text { (natural) }\end{array}$ & $\begin{array}{l}\text { Interaksi antara untai sirkulasi } \\
\text { parallel di dalam dan di luar } \\
\text { bejana } \\
\text { Pengaruh gas yang tak dapat } \\
\text { dikondensasi } \\
\text { Stabilitas } \\
\text { Penyurutan kondensasi }\end{array}$ \\
\hline $\begin{array}{l}\text { Perilaku sistem } \\
\text { penukar panas darurat } \\
\text { dan isolasi kondensor }\end{array}$ & Fenomena tekanan rendah \\
\hline
\end{tabular}




\subsection{Aspek Termal dan Tekanan PRHRS pada SMART}

Aspek termal sistem PRHRS merupakan unsur yang patut diperhatikan dalam kinerja pembuangan sisa panas secara pasif dan kaitannya pada pengujian termohidrolik. Beberapa analisis dilakukan dengan metode simulasi menggunakan kode TASS/SMR dan MARS melalui tahapan nodalisasi sistem reaktor. Selain itu, pendekatan eksperimental termohidrolika juga dilakukan menggunakan fasilitas eksperimental VISTA-ITL, SMARTITL, dan SMART-P. Skenario riset yang dilakukan pun beragam, sehingga sebagian besar menghasilkan analisis yang komprehensif. Pada analisis kinerja termal pada reaktor SMART menggunakan simulasi dengan kode TASS/SMR, skenario yang digunakan berupa kecelakaan rusaknya saluran feedwater dan uap secara transient. Sistem PRHRS reaktor SMART terhubung langsung dengan kedua saluran ini, sehingga skenario kecelakaan ini menjadi titik fokus analisis. Analisis ini dilakukan oleh Y.J. Chung et al [12] hasil riset menunjukkan pergerakan perubahan temperatur cairan pada 150 detik awal, sebagaimana ditunjukkan pada Gambar 5 pada setiap kondisinya. Hasil menunjukkan terjadi gangguan pada 100 detik awal pada temperatur inlet/outlet inti dan generator uap serta pada laju perpindahan panas sistem. Hal tersebut diakibatkan pelepasan uap dan feedwater secara tidak terkontrol sehingga terjadi pembuangan panas yang tidak baik [12].

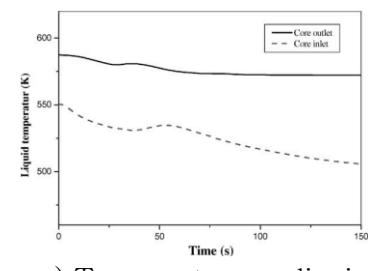

a) Temperatur pendingin pada kondisi kerusakan saluran uap

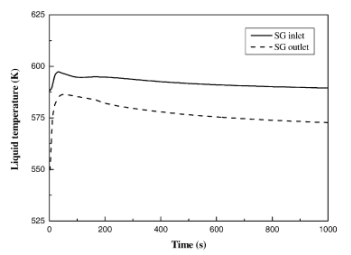

b) Temperature pendingin pada kondisi kerusakan saluran feedwater
Gambar 5. Hasil Kinerja Termal Sistem PRHRS Reaktor SMART Menggunakan Kode TASS/SMR oleh Y.-J. Chung et al. [12].

Selain aspek termal, titik fokus juga patut diarahkan pada kinerja tekanan sistem PRHRS reaktor SMART. Dalam kondisi kerusakan pada saluran uap dan feedwater, performa tekanan pada pressurizer dan generator uap mengalami penurunan seperti ditunjukkan pada Gambar 5. Pada kondisi detik awal pada kecelakaan kerusakan saluran uap (Gambar 6.a), terjadi penurunan tekanan akibat peningkatan kecepatan aliran uap. Selanjutnya terjadi penutupan MSIV sehingga terjadi peningkatan tekanan. Dengan sistem PRHRS, peningkatan tekanan berhasil dicegah dan menurun [12]. Peningkatan tekanan juga terjadi saat kondisi kecelakaan kerusakan saluran feedwater karena terjadi peningkatan temperatur akibat hilangnya kemampuan pembuangan panas (Gambar 6.b). Pembukaan katup keamanan pressurizer memicu kerja PRHRS sehingga tekanan turun dan mencapai kestabilan.

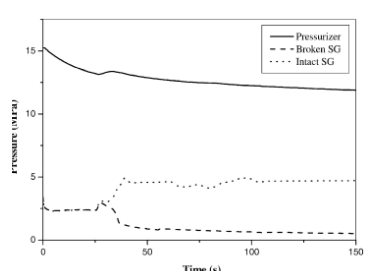

a) Tekanan outlet pressurizer dan generator uap pada kondisi kerusakan saluran uap

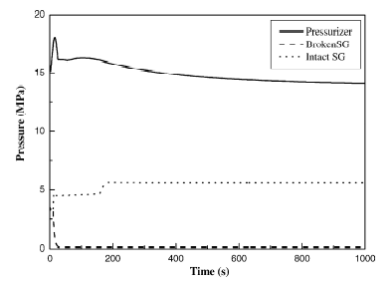

b) Tekanan outlet pressurizer dan generator uap pada kondisi kerusakan saluran feedwater
Gambar 6. Hasil Kinerja Tekanan Sistem PRHRS Reaktor SMART Menggunakan Kode TASS/SMR oleh Y.-J. Chung et al. [12].

Analisis kinerja temperatur serupa menggunakan kode TASS/SMR pada skenario kecelakaan berupa terjadinya retakan pada generator uap dilakukan oleh Kim et al [18]. Kebocoran akibat kerusakan berupa retakan pada generator uap menyebabkan penurunan tekanan pada sistem primer (Gambar 7.a). Skenario kecelakaan ini terjadi pada detik ke1800. Penurunan tekanan tinggi terjadi sesaat setelah aktivasi PRHRS pada detik tersebut. Tekanan pada PRHRS (sisi sekunder) semakin meningkat hingga mencapai titik equilibrium dengan tekanan sisi primer. Gambar 7.b menunjukkan peningkatan tekanan dari PRHRS pada saat aktivasi sistem akibat kecelakaan retakan pada generator uap. Retakan generator uap akan menyebabkan penurunan tekanan pada sistem saluran uap utama. Deteksi penurunan tekanan tersebut memicu aktivasi sistem PRHRS yang kemudian meningkatkan kembali tekanan pada sistem saluran uap utama. Bila dikaji dari sisi temperatur, kecelakaan retakan generator uap tidak 
mengakibatkan kehilangan daya pompa pendingin reaktor, sehingga temperatur sistem pendingin reaktor dapat menurun secara signifikan. Saat aktivasi sistem PRHRS, temperatur generator uap inlet dan outlet menjadi seragam (Gambar 7.c).

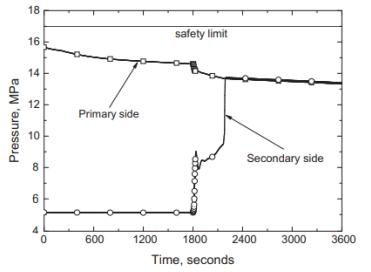

a) Perubahan tekanan sistem pendingin reaktor primer dan sekunder

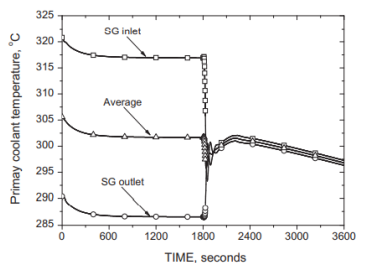

c) Perubahan tekanan sistem sekunder (PRHRS)

Gambar 7. Pengujian Sistem PRHRS (Sisi Sekunder) pada Reaktor SMART oleh H.-K. Kim et al. [18] pada Kondisi Retakan Generator Uap.

Dalam kajian terhadap aspek termohidrolika sistem PRHRS reaktor SMART, studi eksperimental juga dilakukan secara ekstensif melalui fasilitas eksperimental VISTA-ITL dan SMART-ITL oleh KAERI [16]. Perbedaan antara VISTA-ITL dan SMART-ITL adalah skala dari fasilitas eksperimen terhadap ukuran skala 1:1 reaktor SMART. VISTA-ITL merupakan verification by an integral simulation of transients and accidents-integral test loop. Pada VISTA-ITL, hanya terdapat satu rangkaian PRHRS, sedangkan pada SMART-ITL, rangkaian PRHRS berjumlah 4 sesuai dengan desain reaktor SMART. Verifikasi integritas dan kinerja sistem PRHRS reaktor SMART dilakukan oleh Min, et al [23] menggunakan VISTA-ITL. Skenario penelitian dilakukan pada tiga kondisi daya, yaitu $100 \%$ (N1), 20\% (N2), dan 0\% (N3). Aktivasi PRHRS secara otomatis terjadi pada detik ke-110 untuk kondisi daya $100 \%$, pada detik ke-335 untuk kondisi daya 20\%, dan detik ke-248 untuk kondisi daya 0\%. Gambar 4.6a menunjukkan penurunan temperatur secara bertahap sesaat setelah aktivasi PRHRS. Proses pembuangan panas oleh fluida kerja sistem PRHRS memicu peningkatan temperatur fluida secara drastis pada inlet sistem penukar panas PRHRS (Gambar 8.b). Sistem PRHRS tersambung dengan ECT sehingga peningkatan temperatur juga terjadi pada ECT sebagai bagian dari pembuangan panas (Gambar 8.c). Perilaku tekanan PRHRS pada Gambar 8.d menunjukkan peningkatan drastis akibat penutupan MSIF/MFIV. Melalui kerja PRHRS yang membuang panas sisa, tekanan secara bertahap menurun.

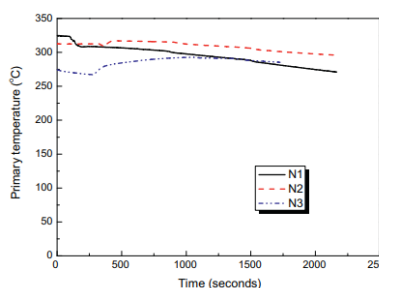

a) Temperatur pendingin pada inlet generator uap

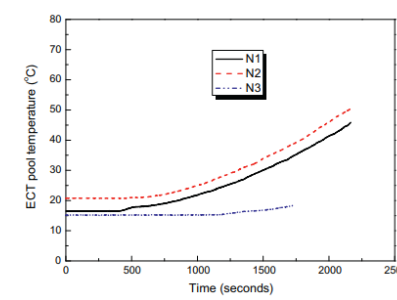

c) Temperatur fluida pada sisi atas ECT

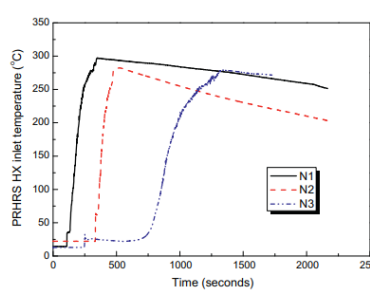

b) Temperatur fluida pada PRHRS

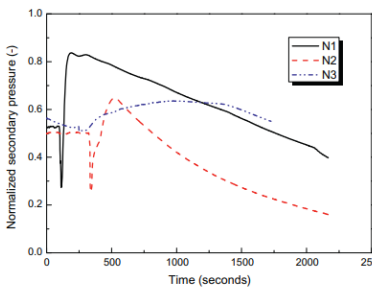

d) Tekanan sistem sekunder
Gambar 8. Hasil Pengujian Transient Sistem PRHRS pada Reaktor SMART Menggunakan VISTA-ITL oleh Min et al. [23].

Reaktor SMART pada kondisi kecelakaan berupa kerusakan pada saluran katup safety pressurizer dan safety injection system (SIS) dianalisis menggunakan fasilitas eksperimental SMART-ITL oleh Y.-S. Kim, et al [24]. Skenario kecelakaan ini dikenal dengan istilah SBLOCA (small break loss of coolant accident). Pada reaktor SMART, kondisi kecelakaan LBLOCA (large break loss of coolant accident) memiliki peluang kecil untuk terjadi dikarenakan desain reaktor yang lebih terintegrasi dan compact. Perubahan kondisi fluida terjadi pada sisi outlet generator uap, ditunjukkan pada Gambar 9.c dan 9.d di mana perubahan terjadi dari panas lanjut menuju jenuh, kemudian dari jenuh menuju subcooling, kemudian kembali ke panas lanjut. Proses pendinginan dengan PRHRS terlihat efektif bekerja dalam menurunkan temperatur pada generator uap. Serupa dengan efek PRHRS terhadap temperatur, Gambar 9.a dan 9.b 
menunjukkan penurunan tekanan sesaat setelah aktivasi PRHRS. Efek aktivasi PRHRS pada kedua kondisi kerusakan juga serupa, menunjukkan keefektifan sistem PRHRS dalam mencegah overpressure dan peningkatan suhu tajam pada sistem primer reaktor SMART.

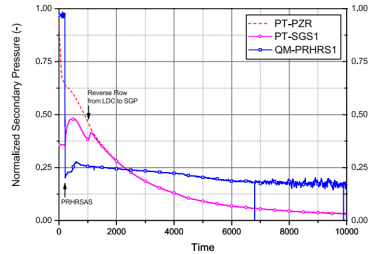

a) Kondisi tekanan pada kerusakan saluran katup safety pressurizer

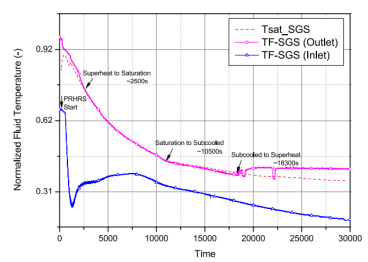

c) Kondisi temperatur pada kerusakan saluran katup safety pressurizer

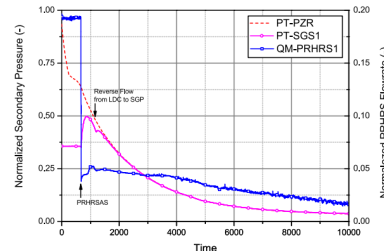

b) Kondisi tekanan pada kerusakan saluran katup SIS

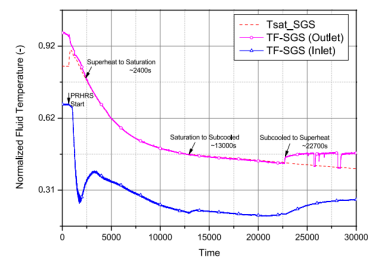

d) Kondisi temperatur pada kerusakan saluran katup SIS
Gambar 9. Hasil Pengujian Kinerja Sistem PRHRS Reaktor SMART pada Fasilitas Eksperimental SMART-ITL oleh Y.-S. Kim et al. [24].

\subsection{Aliran Massa Sirkulasi Alam pada PRHRS SMART}

Pada sistem PRHRS reaktor SMART, pembuangan panas sisa dilakukan secara pasif tanpa daya elektrik. Konsep yang digunakan adalah sirkulasi alam yang menerapkan perbedaan temperatur dan ketinggian dua sumber panas dan sumber pendinginan. Kestabilan kinerja pembuangan panas sisa sistem PRHRS dipengaruhi oleh pergerakan dari fluida kerja pada sistem tersebut. Pada penelitian terhadap performa PRHRS reaktor SMART, kestabilan aliran massa menjadi salah satu titik fokus pengukuran yang dilakukan sebagai validasi terhadap performa pembuangan sisa panas. Kestabilan aliran massa pada sirkulasi alam dipengaruhi oleh berbagai faktor, terutama kondisi sistem yang berayun pada derajat dan periode tertentu [21], pergerakan gelombang laut akibat peningkatan pergerakan pressure drop [25], dan kondisi kemiringan pada derajat tertentu dan berputar akibat peningkatan gaya tangensial sehingga pressure drop meningkat [26]. Namun, reaktor SMART didesain untuk keperluan darat,

sehingga kondisi aliran secara intuitif lebih stabil. Penelitian yang dilakukan oleh Y.-J Chung et al [8] menganalisis aliran massa pada reaktor SMART-P menggunakan kode simulasi MARS dengan membandingkan antara sirkulasi paksa dan alami/natural. Hasil menunjukkan bahwa sirkulasi paksa lebih stabil dibandingkan sirkulasi alami, namun osilasi pada sirkulasi alami pada detik-detik awal masih stabil (Gambar 10.a). Pada ekstensi periode, perubahan kestabilan osilasi mulai terjadi hingga ketidakseragaman pada detik ke-71500 (Gambar 10.c). Selain itu, peningkatan driving head akan meningkatkan kapasitas aliran massa PRHRS, namun peningkatan tersebut memicu ketidakstabilan osilasi (Gambar 10.b).

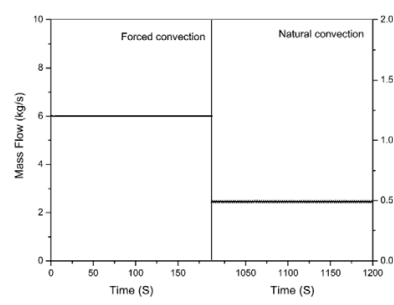

a) Perbandingan aliran massa sirkulasi paksa dan sirkulasi alam
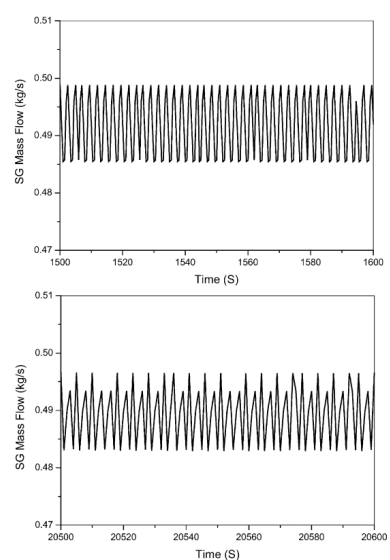

c) Perubahan perilaku/kestabilan osilasi aliran massa pada sirkulasi alami

Gambar 10. Hasil Pengujian Aliran Massa Pada PRHRS Reaktor SMART-P Dengan Kode Simulasi MARS oleh Y.-J Chung et al. [8].

Pendekatan studi eksperimental terhadap aliran massa juga dilakukan menggunakan fasilitas eksperimental VISTA-ITL dan SMART-ITL. Dalam analisis menggunakan VISTA-ITL, Min et al. [23] menguji kestabilan aliran massa pada sisi primer dan sekunder. Pada sisi primer, aliran massa sirkulasi alami PRHRS berosilasi periodik secara stabil pada amplitudo yang rendah (Gambar 11.a). Trend 
pergerakan aliran massa pada sistem sekunder serupa dengan yang terjadi pada sisi primer (Gambar 11.b), namun pada sisi sekunder tidak terjadi osilasi dan lebih stabil.

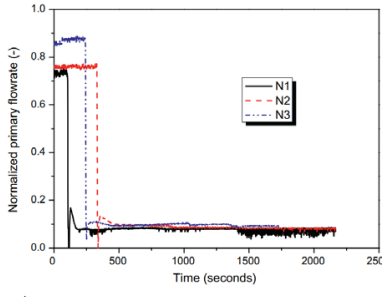

a) Aliran massa pendingin primer

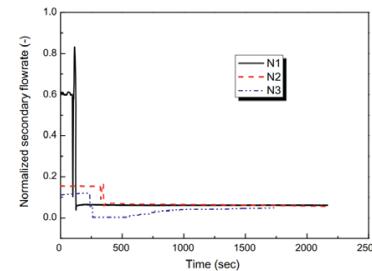

b) Aliran massa pada sistem sekunder
Gambar 11. Hasil Pengujian Aliran Massa pada Reaktor SMART melalui VISTA-ITL untuk Kondisi Daya 100\%

(N1), 20\% (N2), Dan 0\% (N3) oleh Min et al. [23].

Analisis aliran massa pada SMART-ITL yang dilakukan oleh Y.-S Kim et al. [24], khususnya pada kondisi SBLOCA berupa kerusakan saluran katup safety pressurizer dan katup SIS, menunjukkan trend yang sama dengan penelitian yang dilakukan oleh Min et al. [23] (Gambar 12). Namun, aliran massa pada kondisi SBLOCA mengalami osilasi yang cukup tinggi bila dibandingkan dengan penelitian sebelumnya pada kondisi tanpa skenario kecelakaan. Hal ini disebabkan oleh kondisi kerusakan yang terjadi. Namun, ketidakstabilan aliran massa pada kondisi kecelakaan tersebut tidak mempengaruhi kinerja pembuangan sisa panas oleh PRHRS secara signifikan. Studi validasi antara hasil eksperimental dan simulasi menggunakan kode TASS/SMR serta kode MARS dilakukan oleh Y.-j. Chung et al. [27]. Ketiga metode tersebut menunjukkan trend aliran massa yang konsisten, walaupun terdapat perbedaan nilai tinggi khususnya pada kode MARS. Aliran massa pendingin reaktor menurun drastis pada bagian awal-awal akibat transisi dari penggunaan pompa pendingin reaktor menjadi sirkulasi alam menggunakan PRHRS. Penurunan tekanan akibat transisi pada metode kode simulasi TASS/SMR dan MARS lebih tinggi dibandingkan pada hasil eksperimen. Aliran massa meningkat dengan fluktuasi cukup tinggi dalam kondisi pendinginan oleh sirkulasi alam oleh PRHRS. Kode TASS/SMR berhasil menunjukkan peningkatan hingga mencapai perbedaan nilai yang rendah terhadap hasil eksperimen. Trend aliran massa hasil eksperimen dan hasil analisis dengan kode simulasi TASS/SMR serupa pada detik ke-4000 hingga seterusnya. Sedangkan aliran massa pada analisis dengan kode MARS berfluktuasi dengan amplitudo yang semakin besar tanpa mengalami peningkatan sehingga tingkat error pun meningkat.

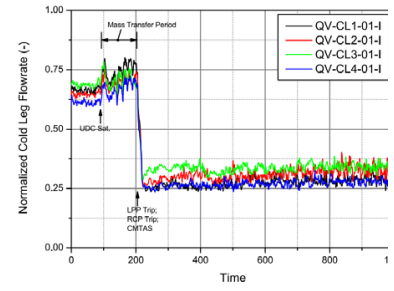

a) Aliran massa pada sisi dingin untuk kondisi kerusakan saluran katup safety pressurizer

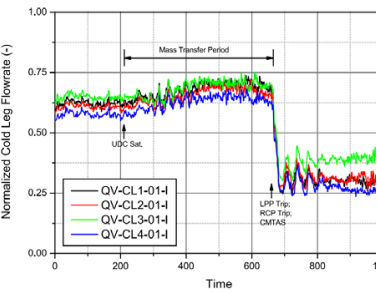

b) Aliran massa pada sisi dingin untuk kondisi kerusakan saluran katup SIS
Gambar 12. Hasil Pengujian Aliran Massa pada Reaktor SMART Melalui Fasilitas Eksperimental SMART-ITL oleh Y.-S Kim et al. [24].

\section{KESIMPULAN}

Berdasarkan paparan kajian sistem PRHRS SMART dengan titik fokus pada aspek keselamatan dan keamanan reaktor, disimpulkan bahwa sistem PRHRS SMART mampu menunjukkan performa pembuangan panas sisa melalui proses sirkulasi alam secara pasif. Data yang dianalisis menunjukkan penurunan bertahap pada tekanan dan temperatur pada sisi generator uap saat PRHRS teraktivasi. Aliran massa sirkulasi alam pada PRHRS mengalami osilasi fluktuatif dan tidak mengalami intervensi parah ketika terjadi kondisi kecelakaan LOCA. Hasil kajian ini mengklarifikasi aspek keamanan yang disampaikan pada kajian oleh Nian et al. [17] terkait prospek penerapan SMR di Asia Tenggara.

\section{UCAPAN TERIMA KASIH}

Ucapan terima kasih penulis sampaikan kepada Riset Inovatif Produktif (RISPRO) LPDP Mandatori PRN PLTN atas bantuan pendanaan dengan nomor kontrak 3/E1/III/PRN/2021 serta Pusat Riset dan Teknologi Keselamatan Reaktor Nuklir (PRTKRN) Organisasi Riset Tenaga Nuklir (BATAN) atas fasilitas yang diberikan berupa observasi fasilitas eksperimental termohidrolika dan akses terhadap sumber literatur. 


\section{DAFTAR ACUAN}

[1] IAEA, Climate Change and Nuclear Power. Vienna: International Atomic Energy Agency, 2016.

[2] G. Locatelli, et al., "Generation IV nuclear reactors: Current status and future prospects," Energy Policy, vol. 61, pp. 1503-1520, 2013, doi: 10.1016/j.enpol.2013.06.101.

[3] GIF, “Annual Report 2019," 2019. doi: 10.3934/math.2020i.

[4] IAEA, "Design Safety Considerations for Water Cooled Small Modular Reactors Incorporating Lessons Learned from the Fukushima Daiichi Accident," IAEA, Vienna, 2016. [Online]. Available: https://wwwpub.iaea.org/MTCD/Publications/PDF/TE-

1785_web.pdf.

[5] M. H. Chang, S. K. Sim, and D. J. Lee, "SMART behavior under over-pressurizing accident conditions," Nucl. Eng. Des., vol. 199, no. 1, pp. 187-196, 2000, doi: 10.1016/S00295493(99)00068-0.

[6] IAEA, Advances in Small Modular Reactor Technology Developments, 2020 Editi. Vienna: IAEA Advanced Reactors Information System (ARIS), 2020

[7] K. H. Bae, H. C. Kim, M. H. Chang, and S. K. Sim, "Safety evaluation of the inherent and passive safety features of the smart design," Ann. Nucl. Energy, vol. 28, no. 4, pp. 333-349, 2001, doi: 10.1016/S0306-4549(00)00057-8.

[8] Y. J. Chung, S. H. Yang, H. C. Kim, and S. Q. Zee, "Thermal hydraulic calculation in a passive residual heat removal system of the SMART-P plant for forced and natural convection conditions," Nucl. Eng. Des., vol. 232, no. 3, pp. 277-288, 2004

10.1016/j.nucengdes.2004.07.002.

[9] Y. J. Chung, S. H. Kim, and K. H. Bae, "Natural circulation heat transfer model development over vertical tube bundle in the condensate heat exchanger," Ann. Nucl. Energy, vol. 94, pp. 759766, 2016, doi: 10.1016/j.anucene.2016.04.037.

[10] H. S. Park, et al., "Contribution of thermalhydraulic validation tests to the standard design approval of SMART," Nucl. Eng. Technol., vol. 49, no. 7 , pp. 1537-1546, 2017, doi: 10.1016/j.net.2017.06.009.

[11] S. A. Olatubosun, "Numerical approach for estimating the conditions for natural circulation in a simple nuclear passive system," Ann. Nucl. Energy, vol. 141, p. 107350, 2020, doi: 10.1016/j.anucene.2020.107350.

[12] Y. J. Chung, et al., "Thermal hydraulic analysis of SMART for heat removal transients by a secondary system," Nucl. Eng. Des., vol. 225, no. 2-3, pp. 257-270, 2003, doi: 10.1016/S00295493(03)00193-6.

[13] Y. J. Chung, et al,, "Passive cooldown performance of a 65 MW integral reactor," Nucl. Eng. Des., vol. 238, no. 7, pp. 1681-1689, 2008, doi: 10.1016/j.nucengdes.2007.12.008

[14] M. W. Na, et al., "Indefinite sustainability of passive residual heat removal system of small modular reactor using dry air cooling tower," Nucl. Eng. Technol., vol. 52, no. 5, pp. 964-974, 2020, doi: 10.1016/j.net.2019.11.003.

[15] J. H. Chun et al., "Safety evaluation of small-break LOCA with various locations and sizes for SMART adopting fully passive safety system using MARS code," Nucl. Eng. Des., vol. 277, pp. 138-145, 2014, doi: 10.1016/j.nucengdes.2014.06.030.

[16] IAEA, "System-Integrated Modular Advanced Reactor (SMART),” 2011. [Online]. Available: https://aris.iaea.org/PDF/SMART.pdf.

[17] V. Nian, "The prospects of small modular reactors in Southeast Asia," Prog. Nucl. Energy, vol. 98, pp. 131-142, 2017, doi: 10.1016/j.pnucene.2017.03.010.

[18] H. K. Kim, et al., "Thermal-hydraulic analysis of SMART steam generator tube rupture using TASS/SMR-S code," Ann. Nucl. Energy, vol. 55, pp. 331-340, 2013, doi: 10.1016/j.anucene.2013.01.007.

[19] R.-J. Park, et al., "Development of severe accident mitigation technology and analysis for SMART," Nucl. Eng. Des., vol. 374, p. 111061, 2021, doi: 10.1016/j.nucengdes.2021.111061.

[20] K. Y. Lee and M. H. Kim, "Modeling of condensation heat transfer for a PRHRS heat exchanger in a SMART-P plant," Nucl. Eng. Des., vol. 238, no. 12, pp. 3253-3262, 2008, doi: 10.1016/j.nucengdes.2008.07.005.

[21] T. Cong, M. Peng, and Z. Zhang, "Preliminary applications of CFD methodology on analysis of the single-phase laminar natural circulation under swing conditions," Prog. Nucl. Energy, vol. 97, pp. 1-10, 2017, doi: 10.1016/j.pnucene.2017.01.001.

[22] IAEA, "Passive safety systems and natural circulation in water cooled nuclear power plants," 2009. [Online]. Available: http://wwwpub.iaea.org/MTCD/publications/PDF/te_1624_we b.pdf.

[23] B. Y. Min, H. S. Park, Y. C. Shin, and S. J. Yi, "Experimental verification on the integrity and performance of the passive residual heat removal system for a SMART design with VISTA-ITL," Ann. Nucl. Energy, vol. 71, pp. 118-124, 2014, doi: 10.1016/j.anucene.2014.03.001.

[24] Y. S. Kim, et al., "Investigation of thermal hydraulic behavior of SBLOCA tests in SMART-ITL facility," Ann. Nucl. Energy, vol. 113, pp. 25-36, 2018, doi: 10.1016/j.anucene.2017.11.013.

[25] B. H. Yan, "Review of the nuclear reactor thermal hydraulic research in ocean motions," Nucl. Eng. Des., vol. 313, pp. 370-385, 2017, doi: 10.1016/j.nucengdes.2016.12.041.

[26] L. He, et al., "Study on natural circulation characteristics of an IPWR under inclined and rolling condition," Nucl. Eng. Des., vol. 317, pp. $81-89$, 2017 ,

doi: 10.1016/j.nucengdes.2017.03.033.

[27] Y. jong Chung, et al., "Validation with the MARS and TASS/SMR codes based on experimental results of a pressurizer safety valve line break at the SMART-ITL facility," Ann. Nucl. Energy, vol. 141, p. 107344, 2020, doi: 10.1016/j.anucene.2020.107344. 